\title{
In vitro evaluation of zwitterion buffers in diluents for freezing ram spermatozoa
}

\author{
FC Molinia *, G Evans, WMC Maxwell \\ Department of Animal Science, University of Sydney, Sydney, NSW 2006, Australia
}

(Received 10 March 1994; accepted 8 August 1994)

\begin{abstract}
Summary - Diluents based on the zwitterion buffers Tes, Hepes and Pipes titrated to $\mathrm{pH} 7.0$ with $\mathrm{NaOH}$ or Tris were compared with Tris-citrate diluents by assessment of post-thawing motility and acrosome integrity of frozen ram spermatozoa. Varying buffer osmolalities between 300 and 360 mosmol had no effect but there was a decrease $(P<0.001)$ in motility between 360 and 420 mosmol. There was a quadratic effect $(P<0.001)$ on motility of increasing glucose concentration in the diluent $(30,85,140$, 195 and $250 \mathrm{mM})$ with a maximum at $85 \mathrm{mM}$. At this sugar concentration, motility was higher $(P<0.001)$ for diluents containing glucose and fructose than lactose, sucrose or trehalose. Inclusion of egg yolk (optimum at $13.5 \% \mathrm{v} / \mathrm{v} ; P<0.05$ ), centrifugation of the diluents $(P<0.01)$, use of low dilution rates (3 or 6-fold; $P<0.05)$ and freezing in pellets rather than minitubes or straws $(P<0.001)$ improved both the motility and acrosome integrity of spermatozoa in the zwitterion diluents. It is concluded that zwitterion buffers are superior to Tris-citrate in ram semen freezing diluents.
\end{abstract}

zwitterion buffer / motility / acrosome integrity / frozen ram spermatozoa

Résumé - Effet de l'addition de tampons amphotères à des dilueurs sur la congélabilité des spermatozoïdes de bélier. Nous avons comparé l'efficacité de dilueurs à base de tampons amphotères TES, HEPES et PIPES ajustés à $\mathrm{pH} 7,0$ avec NaoH ou tris, à celle de milieux à base de tris-citrate, en évaluant la motilité des spermatozoïdes de bélier et lintégrité de leur acrosome après congélation. Entre 300 et 360 milliosmoles, l'osmolarité des tampons n'a aucun effet. Au-delà, et jusqu'à 420 milliosmoles, on observe une baisse significative $(\mathrm{P}<0,001)$ de la motilité. On obtient un effet biphasique sur la motilité en augmentant la concentration de glucose dans le dilueur $(30,85,140,195,250 \mathrm{mM})$ avec un maximum pour $85 \mathrm{mM}$. À cette concentration, la motilité est plus élevée avec le milieu contenant du glucose et du fructose qu'avec ceux contenant du lactose, du sucrose ou du tréhalose $(\mathrm{P}<$ 0,001 ). L'addition de jaune d'œuf (optimum à $13,5 \% \mathrm{v} / \mathrm{v} ; \mathrm{P}<0,05$ ), la centrifugation des dilueurs $(\mathrm{P}<$ $0,01)$, I'utilisation d'un taux de dilution peu élevé $(3$ ou 6 fois; $\mathrm{P}<0,05)$ et la congélation en pastilles plutôt qu'en minitubes ou en minipaillettes $(\mathrm{P}<0,001)$ améliorent la motilité et l'intégrité de l'acrosome des spermatozoïdes congelés dans des milieux contenant un tampon amphotère. Cette étude montre donc que les tampons amphotères sont plus efficaces que le tampon tris-citrate pour les dilueurs utilisés pour la congélation du sperme de bélier.

\section{bélier / mobilité / acrosome / sperme congelé / dilueur / tampon}

* Current address: Department of Biological Sciences, University of Newcastle, Newcastle NSW 2308, Australia 


\section{INTRODUCTION}

Tris-citrate buffer has been used in diluents for freezing spermatozoa of many species. In the ram, varying the diluent composition, osmolality and method of freezing spermatozoa in Tris-citrate-based media has been extensively investigated in the past to improve the post-thawing quality of spermatozoa (reviewed by Salamon and Maxwell, 1994). Zwitterion buffers such as Tes, Hepes and Pipes have pKa values closer to the optimal freezing $\mathrm{pH}$ of 7.0 and vary less than Tris with temperature changes (Good et al, 1966). Comparisons have been made between diluents based on Tris-citrate and zwitterion buffers for freezing semen of boars (Crabo et al, 1972), bulls (Graham et al, 1972; Parrish and Foote, 1980; Garcia and Graham, 1989a), humans (Prins and Weidel, 1986; Weidel and Prins, 1987) and turkeys (Brown et al, 1972), but not rams.

In this study, post-thawing motility and acrosome integrity of frozen ram spermatozoa were evaluated in diluents based on the zwitterion buffers Tes, Hepes and Pipes titrated to $\mathrm{pH} 7.0$ with $\mathrm{NaOH}$ or Tris than in Tris-citrate diluents. The effects of diluent osmolality, sugar concentration and sugar type were initially examined in each buffer system. Subsequently, the effects of egg yolk concentration and centrifugation, semen dilution rate and freezing method were examined to optimise the post-thawing motility and acrosome integrity of ram spermatozoa after freezing semen in zwitterionbuffered diluents.

\section{MATERIALS AND METHODS}

\section{Semen collection, dilution and freezing}

Semen was collected during autumn using an artificial vagina from mature rams of mixed age and breed, housed at the University of Sydney.
Only ejaculates with good wave motion were used (score 4 or 5 on a $0-5$ scale; Evans and Maxwell, 1987), In all experiments, aliquots of semen were diluted in $5 \mathrm{ml}$ glass test-tubes at $30^{\circ} \mathrm{C}$ by slow addition of the buffered freezing diluent. The dilution rates of semen used were 3-fold (Experiments 1-4), 3, 6, 9, 18 or 36-fold (Experiment 5) and 18-fold (Experiment 6 ). All diluents contained $6.0 \%(\mathrm{v} / \mathrm{v})$ glycerol and were buffered to $\mathrm{pH} 7.0$ prior to dilution. All experiments were of factorial arrangement and each experiment was repeated 4 (Experiments 1, 4-6) or 6 (Experiments 2, 3) times (ie 4 or 6 replicates). For each replicate, pooled semen ejaculates from each of 4 (Experiments 1, 4-6) or 6 (Experiments 2, 3) rams was used. In Experiment 6 aliquots of diluted semen (18-fold) were apportioned equally to glass testtubes, $0.25 \mathrm{ml}$ PVC straws (approximately 1.5 $\mathrm{mm}$ in diameter) or $0.25 \mathrm{ml}$ minitubes (approximately $2.5 \mathrm{~mm}$ in diameter), which were sealed with poly-vinyl alcohol or metal beads, respectively. The diluted semen was cooled to $5^{\circ} \mathrm{C}$ over 1.5-2 $\mathrm{h}$ and then frozen in pellet form on dry ice $(0.1 \mathrm{ml} /$ pellet; Evans and Maxwell, 1987), or in straws or minitubes suspended 6 and $4 \mathrm{~cm}$ above liquid nitrogen vapour, respectively (Landers et al, 1992). Frozen pellets, straws and minitubes were transferred into liquid nitrogen for storage for at least $24 \mathrm{~h}$ before thawing.

\section{Preparation of buffers}

All chemicals were purchased from Sigma Chemical Co (Saint Louis, MO) through Bio-Scientific Pty Ltd (Kirrawee, Sydney), and media were made up with de-ionised and filtered water. Seven buffer stock solutions were prepared having the same osmolality (1000 mosmol). These were: a Tris-citrate buffer, $1 \mathrm{M}$ Tris-(hydroxymethyl) aminomethane (Tris) buffered to $\mathrm{pH} 7.0$ with 317 $\mathrm{mM}$ citric acid; and 6 zwitterion buffers: $760 \mathrm{mM}$ $\mathrm{N}$-tris(hydroxymethyl)methyl-2-aminoethane sulfonic acid (Tes) titrated to $\mathrm{pH} 7.0$ with $1 \mathrm{M} \mathrm{NaOH}$; $715 \mathrm{mM}$ Tes titrated to $\mathrm{pH} 7.0$ with $1 \mathrm{M}$ Tris; 785 $\mathrm{mM} \mathrm{N}$-2(hydroxyethylpiperazine- $\mathrm{N}$-2-ethane sulfonic acid (Hepes) titrated to $\mathrm{pH} 7.0$ with $1 \mathrm{M}$ $\mathrm{NaOH} ; 755 \mathrm{mM}$ Hepes titrated to $\mathrm{pH} 7.0$ with $1 \mathrm{M}$ Tris; $395 \mathrm{mM}$ piperazine- $\mathrm{N}-\mathrm{N}$-bis(2-ethane sulfonic acid (Pipes) titrated to $\mathrm{pH} 7.0$ with $1 \mathrm{M}$ $\mathrm{NaOH}$; and $350 \mathrm{mM}$ Pipes titrated to $\mathrm{pH} 7.0$ with $1 \mathrm{M}$ Tris. In all experiments these buffers were diluted to the desired osmolality in the freezing diluents as described below. 


\section{Experiment 1}

To determine the optimum buffer osmolality in the freezing diluent, Experiment 1 was of $5 \times 7$ factorial design and examined 5 osmolalities $(300$, $330,360,390,420 \mathrm{mosmol}$ ) for each of the 7 buffers detailed above. These osmolalities refer to the buffer alone in the diluent. To this diluted buffer was added $6 \%(\mathrm{v} / \mathrm{v})$ glycerol, $18 \%(\mathrm{v} / \mathrm{v})$ egg yolk and $30 \mathrm{mM}$ glucose for all diluents.

\section{Experiment 2}

To optimise diluent sugar concentration, 5 concentrations of glucose $(30,85,140,195$ and 250 $\mathrm{mM}$ ) were combined with each of the 7 buffers. The molarity of the buffers was varied so that the combined buffer and sugar osmolality was 435 mosmols. To this diluted buffer and sugar was added $6 \%(\mathrm{v} / \mathrm{v})$ glycerol and $18 \%(\mathrm{v} / \mathrm{v})$ egg yolk for all diluents.

\section{Experiment 3}

Experiment 3 was of $7 \times 5$ factorial design and examined the 7 buffers containing $85 \mathrm{mM}$ glucose, fructose, lactose, sucrose or trehalose in the freezing diluent. The molarity of the buffers was varied so that the combined buffer and sugar osmolality was 435 mosmol. To this diluted buffer and sugar was added $6 \%(\mathrm{v} / \mathrm{v})$ glycerol and $18 \%$ $(\mathrm{v} / \mathrm{v})$ egg yolk for all diluents.

\section{Experiment 4}

A cloudy precipitate was observed in the zwitterion diluents containing $18 \%(\mathrm{v} / \mathrm{v})$ egg yolk in Experiments 1-3, so this experiment examined the effect of egg yolk centrifugation and concentration in zwitterion-buffered diluents. Seven buffer solutions were prepared: a Tris-citrate (control) diluent and 6 zwitterion diluents. The Tris-citrate diluent contained $360 \mathrm{mM}$ Tris, $114 \mathrm{mM}$ citric acid, $6.0 \% \mathrm{v} / \mathrm{v}$ glycerol and $30 \mathrm{mM}$ glucose. The 6 zwitterion diluents each consisted of a buffer component having an osmolality of 300 mosmols: Tes (228 mM)-NaOH; Tes (215 mM)-Tris; Hepes (236 mM)-NaOH; Hepes (227 mM)-Tris; Pipes
(119 mM)-NaOH; and Pipes (105 mM)-Tris. All contained $6.0 \% \mathrm{v} / \mathrm{v}$ glycerol and $85 \mathrm{MM}$ glucose. Four levels of egg yolk $(0,9.0,13.5,18.0 \% \mathrm{v} / \mathrm{v})$ were examined for each of the 7 buffer systems detailed above. All diluents that contained egg yolk were prepared with or without centrifugation $\left(10000 \mathrm{~g}\right.$ for $10 \mathrm{~min}$ at $20^{\circ} \mathrm{C}$ ) prior to the addition of glycerol and glucose.

\section{Experiment 5}

To evaluate the effect of dilution rate of semen with the zwitterion-buffered diluents, semen was diluted $3,6,9,18$ or 36 -fold in the 7 buffer solutions. The 7 diluents were prepared as for Experiment 4 , centrifuged and contained $13.5 \% \mathrm{v} / \mathrm{v}$ egg yolk only. These diluents were diluted with deionised and filtered water for the dilution rates above 3 -fold so that the final concentration of components and thus the osmolality of the diluted semen was the same (whatever the dilution rate) for each of the 7 buffer solutions.

\section{Experiment 6}

Experiment 6 examined the effect of freezing method with the zwitterion-buffered diluents. The 7 buffer solutions were prepared as for Experiment 5. The semen was diluted 18-fold and frozen in pellets, straws or minitubes as described above.

\section{Assessment of post-thawing motility}

Successful fertilisation of oocytes is dependent on the presence of viable spermatozoa in the female tract at the appropriate time, which in turn depends on the viable life of spermatozoa. Postthawing motility of spermatozoa during incubation was used in all experiments as an estimate of the viable life of spermatozoa. Pellets were thawed in dry 2-ml test-tubes in a waterbath at $37^{\circ} \mathrm{C}$, while straws and minitubes were plunged directly into the waterbath and allowed to thaw and were dried before their contents were emptied into dry 2-ml test-tubes. All samples were diluted with Dulbecco's phosphate-buffered saline (PBS) so that the final concentration of diluted semen represented a 50 -fold dilution of the original undiluted semen sample. The percentage of motile 
spermatozoa was subjectively assessed under a coverslip on a warm stage $\left(37^{\circ} \mathrm{C}\right)$ using phase contrast microscopy (100 x) after 1, 2, 4, 6 and up to $8 \mathrm{~h}$ (Experiments 2, 3) incubation at $37^{\circ} \mathrm{C}$. Samples were coded and presented by an assistant to the assessor in random order, so that the assessor did not know the identity of the individual samples.

\section{Assessment of acrosome integrity}

Changes in the acrosomes of spermatozoa play an important role in the fertilisation process, but spermatozoa require intact (undamaged) acrosomes before they can participate in this process. Thus frozen-thawed spermatozoa from Experiments 4-6 were examined for acrosome integrity to assess their fertilising capacity. Within 30 min of thawing and dilution, a drop of diluted semen was smeared on a slide and allowed to air dry. Smears were stained as for rabbit spermatozoa using a modified staining procedure (in Naphthol Yellow S and Erythrosin B for $14 \mathrm{~min}$; Bryan and Akruk, 1977). Slides were examined by phase contrast microscopy using a $100 \times$ oil immersion objective and white light. Spermatozoa $(n=200$ per slide) were assessed for the percentage of intact acrosomes.

\section{Statistics}

Data for each experiment were subjected to angular transformation and analysis of variance for a split-plot design, with the treatment of the diluents as the mainplots and post-thawing incubation time as subplots. All analyses were performed using Genstat V (Mark 4.03, 1980, Lawes Agricultural Trust, Rothamsted Experimental Station, UK) and $P<0.05$ was considered to be statistically significant.

Motility results are presented as means over the 4 or 5 observation times \pm pooled standard error of means (sem) calculated from the standard error of differences of means in the Anova program. When there were interactions involving incubation time, data were converted to the percentage loss of motile spermatozoa during incubationa. Only interactions showing differences in the percentage loss of motile spermatozoa during incubation are presented. Acrosome integrity results are presented as means of readings conducted at 1 observation time \pm pooled standard error of means (SEM) calculated from the standard error of differences of means in the Anova program.

Significant differences between individual treatment means were determined by the least significant difference procedure where appropriate. Where there were significant interactions, the same error mean square term was used to test the relevant main effects as these were fixed components and no random components were involved in interactions.

\section{RESULTS}

\section{Experiment 1}

There was no effect of buffer osmolality between 300 and 360 mosmol but there was a decrease in post-thawing motility of spermatozoa in buffers with an osmolality of 390 and 420 mosmol $(P<0.001$, table I). There was a difference between buffers: motility was higher in the zwitterion buffers than in Tris-citrate $(P<0.01$, table II) and there was a decrease in motility with incubation time $(P<0.001)$ but no interactions.

\section{Experiment 2}

Glucose concentration in the diluent had a quadratic effect on the post-thawing motility of spermatozoa, which was highest in diluents containing 85 or $140 \mathrm{mM}$ glucose $(P<$

a Percentage loss of motile spermatozoa during incubation =

$\%$ motile sperm at $1 \mathrm{~h}-\%$ motile sperm at 6 or $8 \mathrm{~h} \times 100 \%$ 
0.001 , table I). Motility was also higher in all zwitterion buffers than in Tris-citrate $(P<$ 0.001 , table II). There was a decrease in motility with incubation time $(P<0.001)$ and an interaction between incubation time and glucose concentration $(P<0.05)$. In diluents containing high $(140,195$ and $250 \mathrm{mM})$

Table I. The effect of buffer osmolality, glucose concentration and sugar type in the diluent on the mean ( \pm sem) post-thawing motility of spermatozoa ${ }^{a}$.

\section{Experiment \\ Motile spermatozoa (\%)}

\section{Experiment 1}

Buffer osmolality 300 mosmol 330 mosmol 360 mosmol $390 \mathrm{mosmol}$ 420 mosmol \pm sem

\section{Experiment 2}

Glucose concentration

$\begin{array}{rr}30 \mathrm{mM} & 28.7 \\ 85 \mathrm{mM} & 32.8 \\ 140 \mathrm{mM} & 32.4 \\ 195 \mathrm{mM} & 29.7 \\ 250 \mathrm{mM} & 28.9 \\ \pm \text { sem } & 0.5\end{array}$

\section{Experiment 3}

Sugar type (85 mM)

$\begin{array}{lr}\text { Fructose } & 35.3 \\ \text { Glucose } & 35.3 \\ \text { Lactose } & 25.7 \\ \text { Sucrose } & 24.7 \\ \text { Trehalose } & 24.8 \\ \pm \text { sem } & 0.6\end{array}$

\footnotetext{
a Means averaged for all 7 buffers used, as there were no interactions between buffer osmolality, glucose concentration or sugar type and buffer type.
}

concentrations of glucose, the percentage loss of motile spermatozoa during incubation was lower than in diluents containing low ( 30 and $85 \mathrm{mM}$ ) levels of glucose (68 vs $73 \%)$.

\section{Experiment 3}

The post-thawing motility of spermatozoa was higher for monosaccharides (glucose and fructose) than disaccharides (lactose, sucrose and trehalose) in the diluents $(P<$ 0.001 , table I) but there were no differences within these groups or between Tris-citrate and zwitterion buffers (table II). There was a decrease in motility of spermatozoa with incubation time $(P<0.001)$ and an interaction between incubation time and sugar type $(P<0.001)$. in diluents containing monosaccharides, the percentage loss of motile spermatozoa during incubation was lower than in diluents containing disaccharides (79 vs $88 \%)$.

\section{Experiment 4}

There was a quadratic effect of increasing egg yolk concentration in the diluent $(P<$ 0.001 ) and inclusion of egg yolk and centrifugation of the diluents $(P<0.01)$ improved the post-thawing motility and acrosome integrity of spermatozoa (fig 1). There was a strong improvement in motility and acrosome integrity between 0 and $9 \% \mathrm{v} / \mathrm{v}$ egg yolk and the optimum tested concentration of egg yolk in centrifuged diluents was $13.5 \% \mathrm{v} / \mathrm{v}(P<0.05)$.

There was an interaction between buffer type and incubation time. In diluents containing $z$ witterion buffers, the percentage loss of motile spermatozoa during incubation was lower than in diluents containing Triscitrate ( 35 vs $57 \%$ ). The overall mean motility of spermatozoa was higher in the former than in the latter diluents $(P<0.001$, table II). 
Table II. The effect of freezing ram semen in Tris-citrate (Tc) or zwitterion-buffered diluents (Zwt) a on the mean ( \pm sem) post-thawing motility and acrosome integrity of spermatozoa.

\begin{tabular}{|c|c|c|c|c|c|c|c|}
\hline Experiment $\mathrm{b}$ & 1 & 2 & 3 & 4 & & 5 & 6 \\
\hline \multicolumn{8}{|c|}{ Motile spermatozoa (\%) } \\
\hline Tc & 35.1 & 27.7 & 28.7 & 39.3 & & 44.8 & 37.7 \\
\hline Zwt & $40.5^{\star \star}$ & $31.0^{\star * *}$ & 29.2 & $44.7^{* * *}$ & & $55.7^{\star \star \star *}$ & $41.2^{*}$ \\
\hline \pm sem & 1.3 & 0.6 & 0.7 & 0.8 & & 1.0 & 1.1 \\
\hline Dilution rate & 3-fold & 3 -fold & 3-fold & 3 -fold & 3 -fold & $9,18,36$-fold & 18-fold \\
\hline \multicolumn{8}{|c|}{ Intact acrosomes (\%) } \\
\hline Tc & - & - & - & 43.1 & 51.0 & 55.1 & 50.6 \\
\hline Zwt & - & - & - & 44.0 & $57.6^{\star}$ & $47.0^{*}$ & $40.5^{\star \star \star}$ \\
\hline \pm sem & - & - & - & 1.0 & 2.7 & 2.7 & 1.6 \\
\hline
\end{tabular}

Different from Tris-citrate ${ }^{\star} P<0.05,{ }^{\star \star} P<0.01,{ }^{\star \star \star} P<0.001$. a For all experiments, $Z w t$ values are means averaged for all 6 zwitterion buffers used, as there were no differences between them. ${ }^{b}$ For Experiments $1-6$, means are averaged over the range of buffer osmolalities, glucose concentrations, sugar types, egg yolk concentrations and centrifugations, dilution rates and freezing methods used respectively, as there were no interactions between these variables and buffer type.

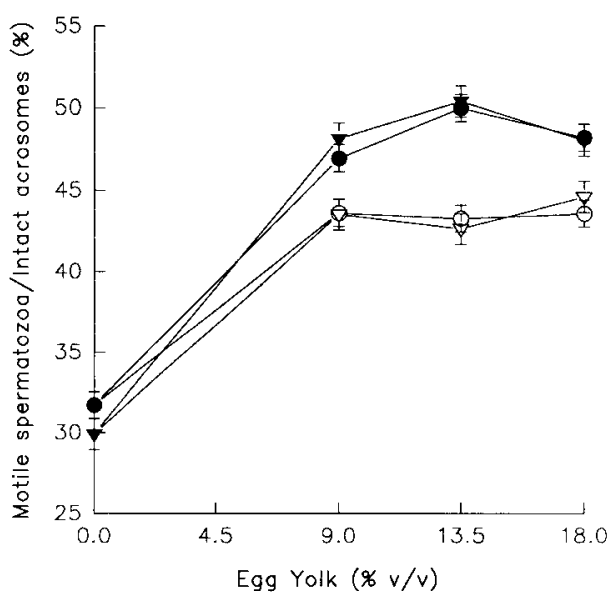

Fig 1. Effect of egg yolk concentration \pm centrifugation of the diluents on the post-thawing motility and acrosome integrity of frozen-thawed spermatozoa (Experiment 4). Values for motile spermatozoa and intact acrosomes have been averaged for the 7 buffers used and are mean percentages \pm sem. O Motility - centrifugation; - motility + centrifugation; $\nabla$ acrosome integrity - centrifugation; $\boldsymbol{\nabla}$ acrosome integrity + centrifugation.

\section{Experiment 5}

There was an interaction between dilution rate and incubation time. In diluents containing semen diluted $6,9,18$ or 36 -fold, the percentage loss of motile spermatozoa during incubation was lower than in diluents containing semen diluted 3-fold (27 vs 51\%). The overall mean motility was higher for dilution rates above 3 -fold $(P<0.001)$ with a maximum between 6 and 18-fold, while acrosome integrity was highest at the 3-fold dilution rate and decreased linearly at the higher dilution rates $(P<0.001$, fig 2$)$.

There was also an interaction between buffer type and incubation time. In diluents containing zwitterion buffers, the percentage loss of motile spermatozoa during incubation was lower than in diluents containing Tris-citrate (27 vs 56\%). The zwitterion-buffered diluents were superior to Tris-citrate in terms of motility at all dilution rates $(P<0.001)$ and acrosome integrity at the 3 -fold dilution rate $(P<0.05$, table II). 


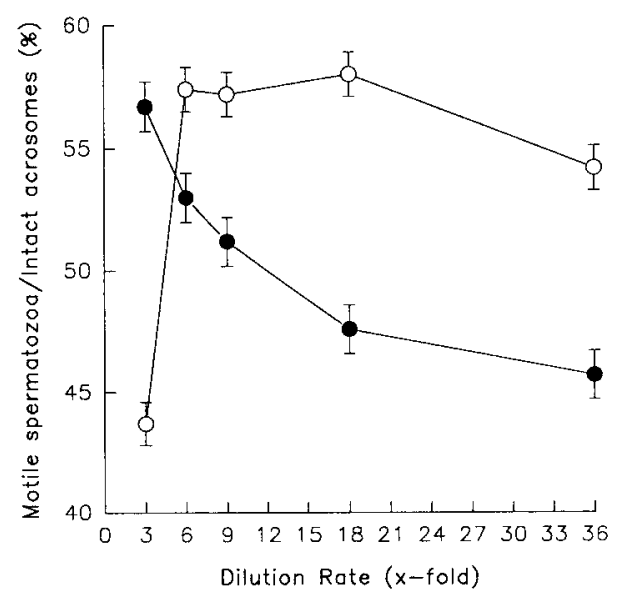

Fig 2. Effect of pre-freezing dilution rate of semen with diluents on the post-thawing motility and acrosome integrity of frozen-thawed spermatozoa (Experiment 5). Values for motile spermatozoa and intact acrosomes have been averaged for the 7 buffers used and are mean percentages \pm sem. O Motility; acrosome integrity.

At higher dilution rates $(9,18,36$-fold $)$, the acrosome integrity of spermatozoa in Triscitrate was better than in zwitterion-buffered diluents $(P<0.05$, table II).

\section{Experiment 6}

There was an interaction between freezing method and incubation time. This was due to a lower percentage loss of motile spermatozoa during incubation for diluted semen frozen in pellets than minitubes and minitubes than straws (fig 3$)$. Motility $(P<0.001)$ and acrosome integrity $(P<0.01)$ of spermatozoa were better for pellets than the other freezing methods and minitubes were superior to straws in terms of motility $(P<$ 0.001 ) but not acrosome integrity (fig 3 ).

Motility was higher $(P<0.05)$ while acrosome integrity was lower $(P<0.001)$ in zwit-

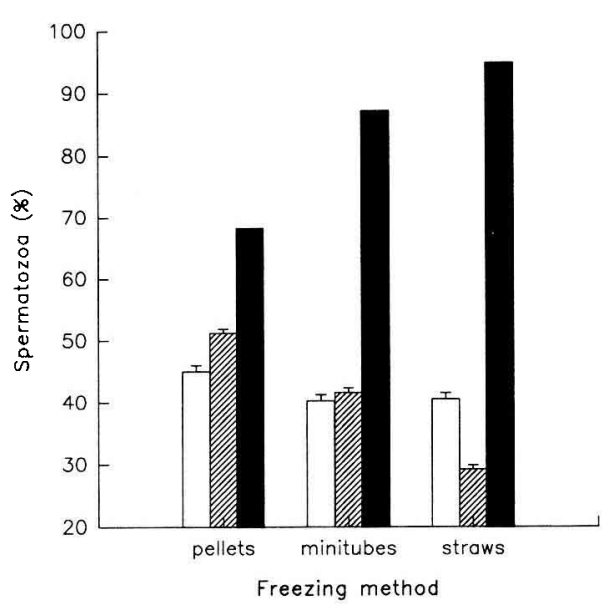

Fig 3. Effect of freezing method on the postthawing motility of spermatozoa during incubation $\left(37^{\circ} \mathrm{C}\right)$ and acrosome integrity in diluents (Experiment 6). Values for intact acrosomes $(\square)$ are mean percentage acrosome integrities $\pm \mathrm{sem}$. Values for motile spermatozoa (Z) are mean percentage motilities \pm sem. Values for loss of motile spermatozoa $(\square)$ are relative measures of the proportionate loss of motility over time expressed as a percentage (see Materials and methods). All values have been averaged for the 7 buffers used.

terion than in Tris-citrate-buffered diluents (table II).

\section{DISCUSSION}

Ram semen freezing diluents buffered to $\mathrm{pH} 7.0$ with Tris-citrate have been used commercially for many years (Watson, 1979). Tris, however, has poor buffering capacity below $\mathrm{pH} 7.5$, but there are zwitterion buffers available for use in the 6.0 to $8.0 \mathrm{pH}$ range (Good et al, 1966). In the present studies, improvements in post-thawing motility and acrosome integrity (Experiment 5) of ram spermatozoa in vitro were observed in zwitterion- compared with Triscitrate-buffered diluents. This may be due 
to the capacity of zwitterion buffers to pick up hydrogen ions in the surrounding medium, thereby aiding the dehydration process (Prins and Weidel, 1986). Tes, Hepes and Pipes were selected because their $\mathrm{pH}$ values were closer to 7.0 and varied less with temperature changes than other zwitterion buffers. Tris-based media can change $\mathrm{pH}$ by more than 1 unit during warming from 0 to $37^{\circ} \mathrm{C}$. These fluctuations can decrease post-thawing cell survival (Salamon and Visser, 1972), which may account for the lower recovery of spermatozoa in our Triscitrate control diluent than in zwitterion diluents. Given this characteristic of Tris, the zwitterion buffers were also titrated with $\mathrm{NaOH}$ in the present study to determine whether Tris could be replaced in the freezing diluent. No effect of titration was found with either Tris or $\mathrm{NaOH}$ in the zwitterionbuffered diluents on post-thawing motility and acrosome integrity of ram spermatozoa.

In these experiments, increasing the diluent buffer osmolality from 300 to 360 mosmol had no effect on post-thawing motility, but at higher osmolalities the viability of spermatozoa was reduced. The latter osmolalities were probably too hypertonic, thereby causing osmotic injury to spermatozoa. Taking into account that these buffer osmolalities are equivalent to diluent osmolalities of 340-400 mosmol, and that a low dilution rate of semen was used in this study (3fold), these results support the findings of Salamon and Visser (1972) using 5-fold dilution, that ram spermatozoa tolerate a wide range of osmolality of freezing media (250-400 mosmol).

Low concentrations of sugar are usually incorporated into semen freezing diluents as a sperm metabolic source, but high sugar concentrations in the freezing diluent have improved cryoprotection of mouse epididymal spermatozoa (Tada et al, 1990). Up to a 7-fold increase in glucose concentrations in Tris-based diluents had no effect on post- thawing motility or fertility of pellet frozenthawed ram spermatozoa (Molinia et al, 1994). The optimum glucose concentration in the present study was between 85 and $140 \mathrm{mM}$ in zwitterion-based diluents, which is 3-5 times the level traditionally incorporated into Tris-based media (Salamon and Visser, 1972), and higher levels may have been toxic. The monosaccharides glucose and fructose were more suitable than the disaccharides lactose, sucrose and trehalose. Type of sugar has no effect in Trisbased diluents for frozen storage of ram semen (Molinia et al, 1994) and Garcia and Graham (1989b) found no difference between glucose, lactose or raffinose in Pipes-Tris-based diluents for freezing dialyzed bull semen. Precipitates from the high egg yolk concentrations in our diluents $(18 \%$ $\mathrm{v} / \mathrm{v}$ ) may have impeded contact between the sugar molecules and spermatozoa, and this may account for the lower viability of spermatozoa in diluents containing disaccharides or low concentrations of glucose $(30 \mathrm{mM})$. There may also be a direct cryoprotective effect of the monosaccharides over the disaccharides in zwitterion diluents. Further, spermatozoa in diluents containing disarrachides lost their motility quicker during post-thawing incubation than in diluents containing glucose or fructose possibly because monosaccharides are more readily metabolizable by spermatozoa (Mann, 1964).

The incorporation of up to $18.0 \% \mathrm{v} / \mathrm{v}$ egg yolk in the pre-freezing diluent is known to improve the post-thawing motility of cryopreserved ram spermatozoa (Salamon and Visser, 1972; Watson and Martin, 1975). The active fraction of egg yolk is the low density lipoprotein (LDL); the protein component binds to the sperm surface and phosphotidylcholine appears to be instrumental in providing cryoprotection (Watson, 1981). In the first 3 experiments a cloudy precipitate was observed before freezing, presumably of cationic egg yolk lipoproteins (Vishwanath 
et al, 1991), in the zwitterion diluents containing $18 \%(\mathrm{v} / \mathrm{v})$ egg yolk, which may have impaired cryoprotection of spermatozoa. Thus, in subsequent experiments, the egg yolk and buffer combination were centrifuged as reported for bull semen freezing diluents (Graham et al, 1972), prior to the addition of glycerol and glucose, and the supernatant was used in the semen diluent. This centrifugation procedure improved both the viability and structural integrity of spermatozoa.

Better post-thawing motility of spermatozoa was achieved for dilution rates above 3-fold compared with 3 -fold (<45\%), with a maximum between 6 and 18 -fold (> 55\%, fig 2). Similar results have been reported for spermatozoa frozen in raffinose-yolkcitrate (Lightfoot and Salamon, 1969) and Tris-based diluents (Visser and Salamon, 1974). In this study, the acrosome integrity of spermatozoa in zwitterion diluents decreased with increasing dilution rate. This result is difficult to interpret, since the final concentration of the various diluent components in diluted semen was constant, thereby ruling out an osmolality effect. Adverse effects of high rates of dilution prior to freezing are not neccessarily due to dilution per se but may be caused by toxic effects of the diluent (Lightfoot and Salamon, 1969). At high dilution rates the concentration of diluent components per sperm cell is much higher than at low dilution rates. Several reports have described adverse morphological and metabolic effects of zwitterion buffers on cell fractions, cells, and tissues (see review by Poole et al, 1982). Thus a toxic effect of the zwitterion buffers on sperm ultrastructure may be occurring at high dilution rates, but this is negligible at low dilution rates ( 3 to 6 -fold; table I).

In the zwitterion diluents examined, minitubes were better than straws but inferior to pellets for freezing spermatozoa (Experiment 6). This result agrees with our preliminary findings in Tris-citrate-based diluents
(Landers et al, 1992). Pellet freezing is generally superior to straw freezing, largely because of its simplicity and reliability (Evans, 1988), although some workers report the opposite (Pontbriand et al, 1989). However, it is likely that the poor results obtained with minitube and straw freezing in this study were partly due to variability in freezing rates in nitrogen vapour (Evans, 1988). Differences between the freezing methods may be minimised with the use of a programmable freezer which can account for the different surface to volume ratios of the freezing packages and the different temperature conductivities of the minitube/straw plugs.

As a comparative measure of the ability of diluents to maintain the viability of spermatozoa after thawing, results were presented as the percentage loss of motile spermatozoa during incubation in all experiments where there were interactions involving incubation time. When the overall mean motility was high the percentage loss of motile spermatozoa during incubation was low and vice versa. Thus diluents with superior motility were likely to sustain the motile cell population longer, while those with lower motility were likely to have a higher incidence of cell mortality.

This study showed that zwitterion-based buffers may be successfully incorporated into diluents for freezing ram spermatozoa. Post-thawing motility of spermatozoa was higher in zwitterion than in Tris-citrate-based diluents and this was independent of buffer type or of titration with $\mathrm{NaOH}$ or Tris in the diluents. Post-thawing motility and acrosome integrity were better maintained in centrifuged egg-yolk-containing zwitterion diluents, at low dilution rates of semen $(3$ to 6-fold) and following pellet-freezing than in minitube- or straw-freezing in these diluents. It remains to be determined whether the improved post-thawing viability of spermatozoa frozen in these novel diluents may be reflected in improved fertility. 


\section{ACKNOWLEDGMENTS}

This work was supported by funds from the Wool Research and Development Corporation (WRDC) and FCM was in receipt of a WRDC postgraduate scholarship. We thank A Souter and A Landers for technical assistance.

\section{REFERENCES}

Brown KI, Graham EF, Crabo BG (1972) Effect of some hydrogen ion buffers on storage and freezing of turkey spermatozoa. J Poult Sci 51, 840-849

Bryan JMD, Akruk SR (1977) A Naphthol Yellow S and Erythrosin B staining procedure for use in studies of the acrosome reaction of rabbit spermatozoa Stain Technol 52, 47-51

Crabo BG, Brown KI, Graham EF (1972) Effect of some buffers on storage and freezing of boar spermatozoa. J Anim Sci 35, 377-382

Evans $G(1988)$ Current topics in artificial insemination of sheep. Aust J Biol Sci 41, 103-116

Evans G, Maxwell WMC (1987) Salamon's Artificial Insemination of Sheep and Goats, Butterworths, Sydney, Australia, 127-130

Garcia MA, Graham EF (1989a) Development of a buffer system for dialysis of bovine spermatozoa before freezing. I. Effect of zwitterion buffers. Theriogenology $31,1021-1028$

Garcia MA, Graham EF (1989b) Development of a buffer system for dialysis of bovine spermatozoa before freezing. Il. Effects of sugars and sugar alcohols on post-thaw motility. Theriogenology 31, 1029-1037

Good NE, Winget GD, Winter W, Connolly TN, Izawa S, Singh RMM (1966) Hydrogen ion buffers for biological research. Biochem 5, 467-477

Graham EF, Crabo BG, Brown KI (1972) Effect of some zwitterion buffers on the freezing and storage of spermatozoa. I. Bull J Dairy Sci 55, 372-378

Landers AJ, Molinia FC, Evans G, Maxwell WMC (1992) Survival of ram spermatozoa trozen in pellets, straws and minitubes. Proc Aust Soc Reprod Biol 24, 20

Lightfoot RJ, Salamon S (1969) Freezing ram spermatozoa by the pellet method. II. The effects of method of dilution, dilution rate, glycerol concentration, and duration of storage at $5^{\circ} \mathrm{C}$ prior to freezing on survival of spermatozoa. Aust J Biol Sci 22, 1547-1560

Mann T (1964) The Biochemistry of Semen and the Male Reproductive Tract. Methuen and Co Ltd, London,
UK, John Wiley and Sons Inc, new York, USA, 266272

Molinia FC, Evans G, Quintana Casares PI, Maxwell WMC (1994) Effect of monosaccharides and disaccharides in Tris-based diluents on motility, acrosome integrity and fertility of pellet-frozen ram spermatozoa. Anim Reprod Sci (in press)

Parrish JJ, Foote RH (1980) Organic buffer for freezing bovine spermatozoa. Proc Amer Soc Anim Sci 72 , 504

Pontbriand D, Howard JG, Schiewe MC, Stuart LD, Wildt DE (1989) The effect of cryoprotective diluent and method of freeze-thawing on survival and acrosomal integrity of ram spermatozoa. Cryobiol 26, 341-354

Poole CA, Reilly HC, Flint MH (1982) The adverse effects of Hepes, Tes and Bes on the ultrastructure of the cultured chick embryo epiphyseal chondrocytes. In Vitro $18,755-765$

Prins GS, Weidel MS (1986) A comparative study of buffer systems as cryoprotectants for human spermatozoa. Fertil Steril 46, 147-149

Salamon S, Visser D (1972) Effect of composition of Tris-based diluent and of thawing solution on survival of ram spermatozoa frozen by the pellet method. Aust J Biol Sci 25, 605-618

Salamon S, Maxwell WMC (1994) Frozen storage of ram semen. I. Processing, freezing, thawing and fertility after cervical insemination. Anim Reprod Sci (in press)

Tada N, Sato M, Yamanoi J, Mizorogi T, Kasai K, Ogawa $S(1990)$ Cryopreservation of mouse spermatozoa in the presence of raffinose and glycerol. $J$ Reprod Fertil $89,511-516$

Vishwanath R, Shannon P, Curson B (1991) Effect of cationic extracts on survival and fertilizing ability of bull sperm. Proc Aust Soc Reprod Biol 23, 127

Visser D, Salamon S (1974) The effect of pellet volume, dilution rate prefreezing and at thawing and of thawing temperature on the survival and acrosome morphology of frozen ram spermatozoa. S Afr J Anim Sci 4, 147-155

Watson PF (1979) The preservation of semen in mammals. Oxf Rev Reprod Biol 1, 282-350

Watson PF (1981) The effects of cold shock on sperm cell membranes. In: Effect of Low Temperature on Biological Membranes (GJ Morris, A Clarke) Academic Press, New York, USA, 189-218

Watson PF, Martin ICA (1975) Effects of egg yolk, glycerol and freezing rate on the viability and acrosomal structures of frozen ram spermatozoa. Aust $J$ Biol Sci 28, 153-159

Weidel L, Prins GS (1987) Cryosurvival of human spermatozoa frozen in eight different buffer systems. $J$ Androl 8, 41-47 